\title{
Produção e composição do leite de vacas em pastagem de capim-elefante (Pennisetum purpureum) suplementado com diferentes fontes de carboidratos
}

\author{
[Milk production and composition of dairy cows grazing elephantgrass (Pennisetum purpureum) supplemented \\ with different sources of carbohydrates] \\ G.A.G. García ${ }^{1}$, R.B. Reis $^{2}$, A.B.D. Pereira ${ }^{3}$, H.M. Saturnino ${ }^{2}$, S.G. Coelho ${ }^{2}$ \\ ${ }^{1}$ Aluno de pós-graduação - EV-UFMG - Belo Horizonte, MG \\ ${ }^{2}$ Escola de Veterinária - UFMG - Belo Horizonte, MG \\ ${ }^{3}$ Aluno de Graduação - EV-UFMG - Belo Horizonte, MG
}

\begin{abstract}
RESUMO
Avaliaram-se os efeitos da silagem de grãos úmidos de milho e da substituição parcial ou total de milho seco por polpa de citrus sobre a produção e a composição do leite de vacas mantidas em pastejo de capimelefante, manejado intensivamente. Foram utilizadas 12 vacas da raça Holandesa, "de alta cruza" distribuídas em quatro tratamentos, em delineamento do tipo quadrado latino. Todas as vacas receberam concentrados que diferiram nas fontes de carboidratos: milho-grão seco moído, polpa de citrus mais milho grão seco moído, polpa de citrus e silagem de grãos úmidos de milho. Não foi detectada diferença $(\mathrm{P}>0,05)$ na produção de leite total, de leite corrigido para gordura (LCG 3,5) e para sólidos (LCS) entre tratamentos. Vacas que receberam milho-grão seco e silagem de milho de alta umidade apresentaram maior porcentagem de proteína e sólidos totais no leite $(\mathrm{P}<0,05)$, e as que receberam polpa de citrus, maior porcentagem de gordura $(\mathrm{P}<0,01)$. As que consumiram silagem de grãos úmidos apresentaram menor valor de nitrogênio ureico no leite $(\mathrm{P}<0,05)$. A ausência de resposta positiva ao processamento do milho pode ser razão do potencial de produção do sistema em pasto e do estresse calórico sofrido pelos animais. Em critérios de pagamento do leite em que a composição não tem valor econômico definido, qualquer uma das fontes de carboidratos testados no presente estudo pode ser utilizada.
\end{abstract}

Palavras-chave: vaca leiteira, capim-elefante, silagem de grão úmido de milho, polpa de citrus

\begin{abstract}
Twelve Holstein dairy cows were assigned to one of four treatments in a $4 x 4$ latin square design. Cows grazed Elephant grass and were supplemented with different concentrates which differed in the carbohydrate source as follows: ground dry corn (MG), citrus pulp plus ground dry corn (MP), citrus pulp $(P C)$, and high moisture corn $(M U)$. There was no difference $(P>0.05)$ between treatments neither in total milk production corrected for $3.5 \%$ nor in milk production corrected for solids. Cows fed ground dry corn and high moisture corn showed higher levels of milk protein and milk total solids $(P<0.05)$ and cows fed citrus pulp showed higher levels of milk fat $(P<0.01)$. Cows that consumed high moisture corn showed lower levels of milk urea nitrogen $(P<0.05)$, indicating that they used nitrogen more efficiently. The lack of positive statistical response in cows consuming high moisture corn could be caused by the production potential of grazing systems as well as by heat stress. For milk payment criteria without considering composition, any carbohydrate source tested may be used for feeding.
\end{abstract}

Keywords: dairy cow, elephant grass, high moisture corn, citrus pulp

Recebido em 5 de outubro de 2009

Aceito em 2 de agosto de 2010

E-mail: galfo0607@hotmail.com 


\section{INTRODUÇÃO}

A agricultura nacional tem apresentado padrão de crescimento notável nos últimos anos, resultado de um cenário econômico e de mercado favoráveis e que têm permitido ao país alcançar patamares de produção e exportação nunca antes atingidos. Nesse contexto, a pecuária tem papel de destaque, razão pela qual observa-se interesse crescente pelo desenvolvimento de novas tecnologias e uso de pastagens para a produção de produtos mais competitivos e de qualidade (Sila et al., 2005).

A produção de leite em pasto está associada à redução de custos financeiros, à redução de doenças como mastites, cetoses e distocias, e ao aumento do teor de ácido linoleico conjugado (CLA), conhecido como um anticancerígeno, encontrado nos produtos alimentícios originados de ruminantes (Gehman et al., 2006).

O manejo intensivo das pastagens permite conseguir aumentos da produção por área e utilização correta dos alimentos concentrados. Apresenta-se como instrumento potente para aumentar a produtividade do sistema, devido ao impacto na produção individual da vaca, ao aumento na lotação da pastagem e, consequentemente, ao aumento da produção de leite por área (Santos et al., 2008).

No mundo tropical, a maioria do leite produzido tem origem nos sistemas de produção que utilizam gramíneas que não conseguem atender às exigências nutricionais de animais com produções acima de 10-12kg leite/dia. Nessas condições, a alternativa que o produtor utiliza com sucesso é trabalhar com vacas cruzadas de menor produção e com baixa dependência de insumos, visando à redução do custo de produção.

Os processos de fermentação na ensilagem de grãos úmidos de milho aumentam a digestibilidade do amido, e podem melhorar a produção e a composição do leite de vacas mantidas em pastagem, manejadas intensivamente. $\mathrm{O}$ objetivo deste estudo foi avaliar os efeitos da silagem de grãos úmidos de milho e da substituição parcial ou total de milho seco por polpa de citrus sobre a produção e composição do leite de vacas mantidas em pastagem de capim-elefante, manejada intensivamente.

\section{MATERIAL E MÉTODOS}

O experimento foi desenvolvido entre os dias 25 de novembro de 2006 a 22 de fevereiro de 2007 em propriedade rural localizada a $850 \mathrm{~m}$ de altitude, $20^{\circ} 04^{\prime} 30^{\prime \prime}$ de latitude sul, $44^{\circ} 20^{\prime} 80^{\prime \prime}$ de longitude oeste. Foram utilizadas 12 vacas da raça Holandesa, sendo oito multíparas (com $26,2 \pm 7,5 \mathrm{~kg}$ leite/dia, 73,1 $\pm 22,7$ dias em lactação e $532 \mathrm{~kg}$ de peso vivo no início do experimento) e quatro primíparas (com $22,5 \pm 3,2 \mathrm{~kg}$ leite/dia, $76,2 \pm 30,3$ dias em lactação e $416 \mathrm{~kg}$ de peso vivo no início do experimento). Os animais foram distribuídos aleatoriamente em três quadrados latinos (4 x 4), sendo as multíparas distribuídas em dois quadrados, e as primíparas em outro. Os tratamentos (Tab. 1) consistiram da substituição parcial ou total do milho-grão seco moído na mistura de concentrados e foram designados: MG - constituido por concentrado com milhogrão seco moído -, MP - constituído por concentrado com milho, grão seco moído mais polpa de citrus -, PC - concentrado com polpa de citrus - e MU - composto por concentrado com silagem de grãos úmidos de milho.

Os grãos úmidos de milho (variedade Pioneer® 30K75) foram colhidos com $34 \%$ de umidade, moídos em moinho dotado de peneira de $3 \mathrm{~mm}$ de diâmetro, inoculados (inoculante Christian Hansen®), compactados e armazenados em silo tipo bunker. Depois foram transferidos e compactados em tambores com capacidade de 200L para posterior mistura e fornecimento aos animais. Cada concentrado foi fornecido individualmente em três arraçoamentos, às 6h30min, 12h30min e 15h30min. Ao final de cada arraçoamento, foram pesadas as sobras para estimar o consumo individual de concentrado por vaca. A forragem foi constituída por capimelefante (Pennisetum purpureum Schum.), manejado em 11 piquetes com, aproximadamente, $2.150 \mathrm{~m}^{2}$ cada um em rotação, com período de ocupação de dois a três dias e 18 a 31 dias de intervalo de desfolha, conforme disponibilidade e altura da forragem. Foram feitas adubações de manutenção equivalentes a $230 \mathrm{~kg} \mathrm{~N} /$ ha durante o período do experimento (84 dias), o que correspondeu a 100kg de ureia por piquete, após a saída dos animais. A taxa de lotação média foi de $5,6 \mathrm{UA} / \mathrm{ha}$. Os piquetes 
contavam com corredores de acesso a áreas de descanso com água e sal mineralizado. A produção do leite (PL) foi medida diariamente do $15^{\circ}$ ao $19^{\circ}$ dia de cada período experimental; no $18^{\circ}$ e $19^{\circ}$ dias, foram coletadas amostras de
$40 \mathrm{~mL}$ de leite, em quatro ordenhas consecutivas. As vacas foram ordenhadas duas vezes ao dia, 6 e 15 horas, e para pesagem e coleta do leite, foram utilizados medidores de leite (Milk meters - Tru-test Ltd, Auckland, New Zealand).

Tabela 1. Porcentagem dos ingredientes e composição dos concentrados com milho grão seco moído (MG), milho grão seco moído mais polpa de citrus (MP), polpa de citrus (PC) e silagem de grão úmido de milho (MU)

\begin{tabular}{lrrrr}
\hline & MG & MP & PC & MU \\
\hline Ingrediente (\% na matéria seca) & & & & 29,4 \\
Farelo de soja & 29,3 & 31,1 & 35,1 & 0,0 \\
Milho seco moído & 65,2 & 32,2 & 0,0 & 0,0 \\
Polpa de citrus moída & 0,0 & 32,4 & 60,7 & 65,2 \\
Silagem grão úmido & 0,0 & 0,0 & 0,0 & 4,3 \\
Premix mineral & 4,3 & 3,1 & 3,1 & 1,2 \\
Bicarbonato de sódio & 1,2 & 1,2 & 1,2 & 0,46 \\
Cloreto de sódio & 0,55 & 0,76 & 0,74 & 74,3 \\
Composição (\%) & & & & 19,6 \\
Matéria seca & 86,1 & 86,9 & 87,2 & 10,1 \\
Proteína bruta & 20,4 & 21,8 & 21,3 & 4,5 \\
Fibra em detergente neutro & 10,8 & 15,9 & 20,5 & 4,4 \\
Fibra em detergente ácido & 5,8 & 11,9 & 18,2 & 93,2 \\
Extrato etéreo & 3,5 & 4,1 & 3,3 & 9,0 \\
DIVMS & 80,5 & 84,7 & 83,7 & 10,8 \\
Cinzas & 9,0 & 8,5 & & 9,5 \\
\hline
\end{tabular}

'Premix mineral: Ca 17\%, P 16,36\%, Mg 3\%, S 5\%, Co 200ppm, Cu 2000ppm, I 180ppm, Mn, 2500ppm, Se $130 \mathrm{ppm}, \mathrm{Zn} 6000 \mathrm{ppm}$. DIVMS: Digestibilidade in vitro da matéria seca.

Nas amostras, foram adicionados $8 \mathrm{mg}$ de bromopol@ para conservação e posterior análise de proteínas, gorduras, sólidos totais e nitrogênio ureico. Os teores de gordura, proteína e sólidos totais foram analisados pela técnica de absorção do comprimento de onda na região do infravermelho, em equipamento Bentley 2000, no Laboratório de Análise da Qualidade do Leite na EV- UFMG. A concentração de nitrogênio ureico no leite (NUL) foi analisada pelo teste enzimático colorimétrico em equipamento Bentley Chemspec 150, na Clínica do Leite, ESALQ-USP. Foram feitas correções de produção de leite para 3,5\% de gordura (PL $3,5 \mathrm{G})$ e para sólidos totais (PL ST), segundo Nutrient... (2001):

PL 3,5G $=(0,35 \times$ PL $)+(16,2 \times$ PG $)$ e $\mathrm{PL} \mathrm{ST}=(12,3 \times \mathrm{PG})+(6,56 \times \mathrm{P}$ SNG $)-(0,0752$ $x$ PL), em que

$\mathrm{PL}=$ produção de leite $(\mathrm{kg})$;

$\mathrm{PG}=$ produção de gordura $(\mathrm{kg})$;

$\mathrm{P}$ SNG = produção de sólidos não gordurosos ( $\mathrm{kg})$
As análises estatísticas foram executadas pelo modelo misto do SAS/1989 6.12 (Proc Mixed) para quadrado latino com análise de contrastes, segundo o modelo:

$Y i j k l=\mu+\mathrm{Si}+\mathrm{Pj}+\mathrm{Vk}(\mathrm{i})+\mathrm{Tl}+\mathrm{PT} \mathrm{j} l+$ Eijkl, em que

Yijkl= observação do quadrado i, no período $\mathrm{j}$, da vaca $\mathrm{k}$, do tratamento $\mathrm{l}$;

$\mu=$ média geral;

$\mathrm{Si}=$ efeito do quadrado $\mathrm{i}$;

$\mathrm{Pj}=$ efeito do período $\mathrm{j}$;

$\mathrm{Vk}(\mathrm{i})$ = efeito da vaca $\mathrm{k}$ (dentro do quadrado i);

$\mathrm{Tl}=$ efeito do tratamento 1 ;

Eijkl = variação aleatória atribuída ao quadrado i, no período j, da vaca $\mathrm{k}$, no tratamento 1 .

\section{RESULTADOS E DISCUSSÃO}

A produção e a composição do leite e a eficiência de nutrientes (Tab. 2) das vacas que receberam milho-grão seco moído e silagem de grãos úmido de milho apresentaram maior 
porcentagem de proteína comparado com as vacas que receberam polpa de citrus. A excreção de proteína no leite é dependente do fluxo de proteína no intestino delgado e a principal fonte de proteína para o intestino delgado é a proteína microbiana, majoritariamente das bactérias ruminais. Assim, quanto mais aminoácidos forem absorvidos, mais substrato haverá para a síntese de caseínas e proteínas do leite (Mattos, 2005). A síntese de proteína microbiana é dependente da disponibilidade de energia e esqueletos de carbono durante o metabolismo ruminal de carboidratos (Hall e Herejk, 2001). Carboidratos rapidamente fermentáveis, como o amido, têm sido associados ao maior conteúdo de proteína no leite devido à maior energia disponível e à maior quantidade de propionato $\mathrm{e}$ proteína microbiana produzida (Jenkins e McGuire, 2005). Dietas que são pobremente fermentadas diminuem a produção microbiana e os precursores para a produção de glicose e lactose no leite (Allen, 2001).

Tabela 2. Produção e composição do leite e eficiência de nutrientes de vacas leiteiras em pastagem de capim elefante suplementada com diferentes fontes de carboidratos

\begin{tabular}{lrrrrrrrr} 
& \multicolumn{4}{c}{ Concentrado } & \multicolumn{4}{c}{ Contrastes } \\
\cline { 2 - 9 } & \multicolumn{1}{c}{ MG } & \multicolumn{1}{c}{ MP } & \multicolumn{1}{c}{ PC } & MU & EPM & MGxMU & MPxPC & MPx(MG+PC) \\
\hline Leite, kg/dia & 22,4 & 21,0 & 21,6 & 22,5 & 0,38 & 0,88 & 0,38 & 0,26 \\
LCG 3,5\% & 20,2 & 19,4 & 20,4 & 20,4 & 0,38 & 0,90 & 0,97 & 0,32 \\
LCS & 19,5 & 18,8 & 19,4 & 19,7 & 0,34 & 0,97 & 0,86 & 0,38 \\
Gordura, \% & 3,34 & 3,49 & 3,59 & 3,33 & 0,03 & 0,86 & 0,01 & 0,85 \\
Gordura, kg/dia & 0,76 & 0,74 & 0,78 & 0,77 & 0,02 & 0,94 & 0,62 & 0,37 \\
Proteína, \% & 2,96 & 2,96 & 2,88 & 2,95 & 0,01 & 0,90 & 0,04 & 0,19 \\
Proteína, kg/dia & 0,66 & 0,62 & 0,62 & 0,66 & 0,01 & 0,89 & 0,11 & 0,43 \\
Sólidos, \% & 11,51 & 11,69 & 11,71 & 11,54 & 0,03 & 0,65 & 0,03 & 0,31 \\
Sólidos, kg/dia & 2,57 & 2,46 & 2,52 & 2,60 & 0,04 & 0,96 & 0,62 & 0,38 \\
Leite/CMS conc. & 2,93 & 2,72 & 2,89 & 3,10 & 0,06 & 0,42 & 0,79 & 0,15 \\
NUL ${ }^{7}$ (mg/dL) & 16,28 & 17,21 & 16,73 & 15,32 & 0,22 & 0,06 & 0,44 & 0,16 \\
\hline
\end{tabular}

MG: milho grão seco moído; MP: milho grão seco moído mais polpa de citrus; PC:polpa de citrus; MU:silagem de grão úmido de milho. EPM = erro-padrão da média; LCM:leite corrigido para gordura; LCS:leite corrigido para sólidos totais; CMS:consumo matéria seca; NUL:nitrogênio ureico no leite.

A concentração de NUL foi menor nas vacas que consumiram silagem de grãos úmidos de milho comparada com as que receberam polpa de citrus $(\mathrm{P}<0,01)$ e milho-grão seco moído $(\mathrm{P}<0,06)$. O excesso de amônia produzido no rúmen é absorvido e transportado no sangue até o fígado e os rins, onde é transformado em ureia. Parte da ureia circulante no sangue volta ao rúmen via saliva. Assim, a ureia é muito menos tóxica no sangue que a amônia e é também um constituinte normal da fração nitrogenada não proteica do leite. A concentração de ureia no sangue está altamente relacionada com a concentração de NUL (Bucholtz e Johson, 2007). Um alto conteúdo de NUL pode ser explicado pela menor energia de liberação dentro do rúmen, que limitaria o uso do nitrogênio produzido na fermentação ruminal e ocasionaria aumento na absorção de amônia.

Sutton et al. (1987) relataram menor digestibilidade do nitrogênio, grande digestibilidade da FDN e similar digestibilidade da matéria orgânica quando vacas lactantes foram alimentadas com carboidratos fibrosos de alta degradabilidade (polpa de citrus ou de beterraba) comparadas com alimentos ricos em amido. Aparentemente dietas com maior quantidade de amido de alta disponibilidade têm melhor utilização do nitrogênio. As vacas que consumiram silagem de grãos úmidos apresentaram mais baixos valores de NUL $(15,32 \mathrm{mg} / \mathrm{dL})$, e podem indicar que utilizaram mais eficientemente o nitrogênio. A estimação da concentração média de NUL pode ser utilizada para ajudar a determinar o nível de proteína ótimo da dieta e saber a eficácia com que está sendo utilizado o nitrogênio oriundo dessa proteína (Broderick et al., 1990). Segundo Grant et al. (2007), o valor médio de NUL em um um rebanho leiteiro deve estar entre $12-16 \mathrm{mg} / \mathrm{dL}$, respectivamente. Valores médios acima de $16 \mathrm{mg} / \mathrm{dL}$ indicariam deficiência na fermentação de carboidratos não fibrosos, um excesso de proteína na dieta e/ou desequilíbrio entre as disponibilidades de energia e nitrogênio dentro do rúmen (Grant, 2005), e poderiam estar 
correlacionados a problemas de fertilidade (Tamminga, 1992; Staples et al., 1993).

A utilização de dietas com teor excessivo de PB (concentrados com PB $>16 \%$ e forragens com $\mathrm{PB}>12 \%$ ) resulta em teor alto de $\mathrm{N}$-ureico no plasma e no leite. Isso pode prejudicar o desempenho reprodutivo das vacas e aumentar as exigências em energia, uma vez que são necessárias 13,3kcal de energia digestível para excretar um grama de nitrogênio (Santos et al., 2001). Neste estudo, a porcentagem média de proteína no leite em todos os tratamentos $(2,94 \%)$ foi baixa, e o NUL, alto, com exceção das vacas que consumiram grão úmido de milho), devido, possivelmente, ao elevado teor de proteína das dietas $(>17 \%)$ e ao pouco espaçamento entre o oferecimento dos concentrados durante o dia - 6h30min, 12h30min e 15h30min, período no qual os animais apresentaram baixo consumo de forragem. Embora vacas que tenham consumido silagem de grãos úmidos de milho tenham apresentado produção de leite numericamente maior (total, LCG e LCS), a ausência de resposta ao processamento do milho pode ter sido causada pelo potencial de produção, próprio dos sistemas de produção em pasto e pelo estresse calórico sofrido por estes animais. Isso devido à inexistência de sombra e às temperaturas e umidades relativas do ar apresentadas nos meses de dezembro, janeiro e fevereiro, que, segundo o índice de temperatura e umidade (Thom, 1959), indicariam que os animais encontravam-se sob estresse térmico.

Soriano et al. (2000), Reis et al. (2001) e Delahoy et al. (2003) não encontraram diferenças na produção e na composição do leite quando suplementaram vacas que pastejavam gramíneas de clima temperado com milho processado de diferentes maneiras (milho seco moído ou quebrado, milho úmido grosso, milho úmido moído ou milho floculado). Broderick et al. (2002) não observaram diferenças na produção e na composição do leite, nem na eficiência alimentar quando a silagem de grãos úmidos de milho substituiu o milho seco em dietas para vacas confinadas. Segundo os autores, a digestão pós-ruminal do amido no tratamento com milho seco compensou a alta digestibilidade ruminal apresentada pelas vacas que consumiram milho úmido.
Oba et al. (2003) não encontraram diferenças $(\mathrm{P}>0,05)$ na produção nem na composição do leite, ao utilizarem milho seco ou silagem de grãos úmidos de milho em dietas para vacas leiteiras com baixa porcentagem de amido (21\% da matéria seca), mas observaram diminuição $(\mathrm{P}<0,05)$ na produção de leite e de gordura quando a silagem de grãos úmidos substituiu o milho seco em dietas com alta porcentagem de amido (33\%). Wilkerson et al. (1997), ao trabalharem em ambiente controlado $\left(16^{\circ} \mathrm{C}\right.$ de temperatura e $65 \%$ de umidade no ar) e em sistema de alimentação TMR, compararam grãos de milho seco (grosso e moído) com silagem de grãos úmido de milho (grosso e moído). Verificaram maior produção de leite $(\mathrm{P}<0,10)$ e proteína $(\mathrm{P}<0,05)$, quando as silagens de grãos úmidos substituíram os milhos secos. É importante ressaltar, neste experimento, que as vacas que consumiram grão úmido de milho apresentaram maior produção de calor metabólico (36,95 vs 35Mcal/dia).

Knowlton et al. (1998), em um experimento com delineamento similar ao experimento de Wilkerson et al. (1997), também, ao compararem milho seco com silagem de grãos úmidos de milho, ambos com diferentes formas de processamento (moído e grosso) e em sistema de produção comercial, não encontraram diferenças $(\mathrm{P}>0,05)$ na produção nem na composição do leite. Os autores atribuíram a não diferença na produção de leite, a favor dos tratamentos com grãos úmidos, às altas temperaturas ambientais durante $o$ transcurso do experimento, que ocasionaram alto estresse calórico nos animais. $\mathrm{Wu}$ et al. (2001) observaram, em vacas em pastejo de gramíneas de clima temperado, maior produção do leite, mas com diminuição na porcentagem de gordura $(\mathrm{P}<0,05)$, quando substituíram milho seco quebrado por silagem de grãos úmidos de milho, 22,9kg leite/dia vs. $20,5 \mathrm{~kg}$ leite/dia.

O LCG não foi diferente entre os tratamentos $(\mathrm{P}>0,05)$. San Emeterio (1998) observou que vacas alimentadas com silagem de grãos úmidos produziram mais leite $(39,8 \mathrm{~kg} /$ dia $)$ e proteína $(3,11 \mathrm{~kg} / \mathrm{dia})$ em relação às que receberam grãos secos de milho $(38,0 \mathrm{~kg}$ de leite e $3,08 \mathrm{~kg}$ de proteína/dia) na dieta. Wilkerson et al. (1997) também observaram maior produção de leite $(2,6 \mathrm{~kg} / \mathrm{dia})$ e proteína $(0,08 \mathrm{~kg} / \mathrm{dia})$ quando utilizaram silagem de grãos úmidos de milho. 
Com relação à substituição de milho por polpa de citrus, Martinez (2004) não observou diferenças na produção e na composição do leite assim como na eficiência nutricional, quando substituiu o milho seco por polpa de citrus em diferentes proporções $(25,50$ e $75 \%)$ em vacas que pastejavam capim-elefante. Delahoy et al. (2003) e Gehman et al. (2006) observaram diminuição na porcentagem de proteína quando substituíram milho seco por polpa de citrus em vacas em pastejo de gramíneas de clima temperado. Mansfield et al. (1994) e Voelker e Allen (2003) encontraram menor porcentagem de proteína $(\mathrm{P}<0,05)$ e maior porcentagem de gordura, mas sem diferenças quanto à produção diária $(\mathrm{P}>0,05)$, em vacas confinadas, quando a polpa de beterraba substituiu o milho seco em várias proporções. Leiva et al. (2000), Solomon et al. (2000) e Broderick et al. (2002) observaram menores porcentagens de proteína e gordura, quando a polpa de citrus substituiu as fontes de amido (milho seco ou a silagem de grão úmido de milho), em vacas confinadas. Esses últimos autores verificaram maior concentração de NUL.

Clark e Armentano (1997) e Santos et al. (2001) não observaram diferença $(\mathrm{P}>0,05)$ na produção de leite nem na porcentagem de proteína do leite, quando a polpa de citrus substituiu milho seco ou floculado em dietas TMR. Nesse último trabalho, foi observado aumento significativo na produção de gordura $(\mathrm{P}<0,05)$. Hristov et al. (2003) substituíram cevada por milho seco associado com polpa de citrus em vacas confinadas e não observaram diferenças na produção nem na composição do leite. Segundo Ekinci e Broderick (1997), o processamento dos grãos melhora a digestibilidade ruminal, mas nem sempre a produção do leite. Muitos fatores como genética, época de parição e clima podem limitar a produção de leite e a síntese de proteína microbiana no rúmen.

\section{CONCLUSÕES}

Em sistemas de pagamento do leite em que a composição não tem valor econômico definido, qualquer uma das fontes de carboidratos testados no presente estudo pode ser recomendada. A utilização de concentrados à base de amido resultou em melhor eficiência no uso da proteína bruta da dieta, o que deve ser levado em consideração em vacas mantidas em pastagens adubadas e com alta concentração de proteína.

\section{REFERÊNCIAS BIBLIOGRÁFICAS.}

ALLEN, M. Formulating lactating cows diets for carbohydrates. In: WESTERN DAIRY MANAGEMENT CONFERENCE, 5., 2001, Las Vegas. Proceedings... Las Vegas, 2001. p.79-86.

BRODERICK, G.A.; MERTENS, D.R.; SIMONS R. Efficacy of carbohydrate sources of milk production by cows fed diets based on alfalfa silage. J. Dairy Sci., v.85, p.1767-1776, 2002.

BRODERICK, G.A.; RICKER, D.B.; DRIVER, L.S. Expeller soybean meal and corn by-products versus solvent soybean meal for lactating dairy fed alfalfa as sole forage. J. Dairy Sci., v.73, p.453-462, 1990.

BUCHOLTZ, H.; JOHNSON, T. Use of milk urea nitrogen in herd management. In: ANNUAL TRI-STATE DAIRY NUTRITION CONFERENCE, 16., 2007, Fort Wayne. Proceedings... Fort Wayne, 2007. p.63-67.

CLARK, P.W.; ARMENTANO, L.E. Influence of particle size on the effectiveness of beet pulp fiber. J. Dairy Sci., v.80, p.898-904, 1997.

DELAHOY, J.E.; MULLER, L.D.; BARGO, F. et al. Supplemental carbohydrate sources for lactating dairy cows on pasture. J. Dairy Sci., v.86, p.906-915, 2003.

EKINCI, C.; BRODERICK, A.G. Effect of processing high moisture ear corn on ruminal fermentation and milk yield. J. Dairy Sci., v.80, p.3298-3307, 1997.

GEHMAN, A.M.; BERTRAND, J.A.; JENKINS, T.C. et al. The effect of carbohydrate source on nitrogen capture in dairy cows on pasture. J. Dairy Sci., v.89, p.2659-2667, 2006.

GRANT, R.J.; DRUDICK, D.; KEOWN, J.F. Milk urea nitrogen testing. Lincoln: IANR University of Nebraska. Disponível em: <http://www.ianrpubs.unl.edu/dairy/g1298.htlm> . Acessado em 20 nov 2007.

GRANT, R.J. Optimizing starch concentrations in dairy rations. In: ANNUAL TRI-STATE DAIRY NUTRITION CONFERENCE, 14., 2005, Fort Wayne. Proceedings... Fort Wayne, 2005. p.73-79. 
HALL, M.B.; HEREJK, C. Differences in yields of microbial crude protein from in vitro fermentation of carbohydrates. J. Dairy Sci., v.84, p.2486, 2001

HRISTOV, A.N.; ROPP, J.K. Effect of dietary carbohydrate composition and availability on utilization of ruminal ammonia nitrogen for milk protein synthesis in dairy cows. J. Dairy Sci., v.86, p.2416-2427, 2003

JENKINS, T.C.; McGUIRE, M.A. Effects of nutrition on milk composition: A 25-year review of research reported in the journal of Journal of Dairy Science. In: ANNUAL TRI-STATE DAIRY NUTRITION CONFERENCE, 14., 2005, Fort Wayne. Proceedings... Fort Wayne, 2005. p.51-57.

KNOWLTON, K.F.; GLENN, B.P.; ERDMAN, R.A. Performance, ruminal fermentation, and site of starch digestion in early lactation cows fed corn grain harvested and processed differently. J.Anim. Sci., v.81, p.1972-1984, 1998.

LEIVA, E.; HALL, M.B.; VAN HORN, H.H. Performance of cattle fed citrus pulp or corn products as sources of neutral detergent-soluble carbohydrates. J. Dairy Sci., v.83, p.2866-2875, 2000 .

MANSFIELD, H.R.; STERN, M.D.; OTTERBY, D.E. Effects of beet pulp and animal by-products on milk yield and in vitro fermentation by rumen microorganisms. J. Dairy Sci., v. 77, p.205-216, 1994.

MARTINEZ, J.C. Substituição do milho moído fino por polpa cítrica peletizada no concentrado de vacas leiteiras mantidas em pastagens de capim elefante durante o outono - inverno. 2004. 121f. Dissertação (Mestrado) - Escola Superior de Agricultura "Luiz de Queiroz", Universidade de São Paulo, Piracicaba.

MATTOS, W. Influência da nutrição sobre a composição de sólidos totais no leite. In: SIMPÓSIO SOBRE BOVINOCULTURA LEITEIRA, 5., 2005, Piracicaba. Anais... Piracicaba, 2005.

NUTRIENTS requirements of dairy cattle. 7.ed. Washington: National Academy of Sciences, 2001. 408p.
OBA, M.; ALLEN, M.S. Effects of corn grain conservation method on feeding behavior and productivity of lactating dairy cows at two dietary starch concentrations. J. Dairy Sci., v.86, p.174-183, 2003.

REIS, R.B.; SAN EMETERIO, F.; COMBS, D.K. Effects of corn particle size and source on performance of lactating cows fed direct-cut grass-legume forage. J. Dairy Sci., v.84, p.429441, 2001.

SANTOS, F.A.P.; MARTINEZ, J.C.; GRECO, L.F. et al. Nutrição das vacas em lactação, no período chuvoso, para a produção intensiva de leite em pasto.Cad. Tec. Vet. Zootec., n.57, p.1$117,2008$.

SANTOS, P.F.A.; MENEZES, J.M.P.; CORRÊA, J.M. et al., Processamento do grão de milho e sua substituição parcial por polpa de citrus peletizada sobre o desempenho, digestibilidade de nutrientes e parâmetros sanguineos em vacas leiteiras. Acta Scientiarum, v.23, p.923-931, 2001.

SILA, C.S.; DO NASCIMENTO, J.; MONTAGNER, D.B. Desafios da produção intensiva de bovinos de corte em pastagens. In: SIMBOI-I SIMPÓSIO SOBRE DESAFIOS E NOVAS TECNOLOGIAS NA BOVINOCULTURA DE CORTE, 1., 2005, Brasília. Anais... Brasília: UPIS, 2005.

SOLOMON, R.; CHASE, L.E.; BEMGHEDALIA D. et al. The effect of nonstructural carboydrate and addition of full fat extruded soybeans on the concentration of conjugated linolenic acid in the milk fat of dairy cows. $J$. Anim. Sci., v.83, p.1322-1329, 2000.

SORIANO, F.D.; POLAN, C.E.; MILLER, C.N. Milk prodution and composition, rumen fermentation parameters, and grazing behavior of dairy cows supplemented with different forms and amounts of corn grain. J. Dairy Sci., v.83, p.1520-1529, 2000.

STAPLES, C.R.; GARCIA, B.C.; OLDICK, B.S. et al. Protein intake and reproductive performance of dairy cows: A review, a suggested mechanism and blood and milk urea measurements. In: 4 th ANNUAL FLORIDA RUMINANT NUTRITION SYMPOSIUM, 4., 1993, Gaineville. Proceedings... Gaineville: University of Florida, 1993. p.37. 
SUTTON, J.D.; BINES, J.A.; MORANT, S.V. et al. A comparison of starchy and fibrous concentrates for milk production, energy utilization and hay intake by friesian cows. $J$. Agric. Sci., v.109, p.375-386, 1987.

TAMMINGA, S. Nutrition management of dairy cows as a contribution to pollution control. $J$. Dairy Sci., v.75, p.345-357, 1992.

THOM, E.C. The discomfort index. Weatherwise, v.12, p.57-60, 1959.

VOELKER, J.A.; ALLEN, M.S. Pelleted beet pulp substituted for high-moisture corn: 1.effects on feed intake, chewing behaviour, and milk production of lactating dairy cows. J. Dairy Sci., v.86, p.3542-3552, 2003.
WILKERSON, V.A.; GELNN, B.P.; McLEOD, K.R. Energy and nitrogem balance in lactating cows fed diets containing dry or high moisture corn in either rolled or ground form. J. Dairy Sci., v.80, p.2487-2496, 1997.

WU, Z.; MASSINGILL, L.J.; WALGENBACH R.P. Cracked dry or finely ground high moisture shelled corn as a supplement for grazing cows. $J$. Dairy Sci., v.84, p.2227-2230, 2001. 